\title{
Multiobjective Approach in Developing Oil Production Enterprise's Production Strategy
}

\author{
Irina Vladimirovna Osinovskaya
}

\author{
Associated Professor Of "Management in Fuel-Energy complex" Department, Russian Federation, Tyumen
}

Email: osinovskaya79@mail.ru

\section{Olga Gennadyevna Yakunina}

\section{Olga Viktorovna Lenkova}

Institute of Management \& Business, Department of Energy complex Management, Tyumen State oil and gas University, Russia, 625000, Tyumen, Volodarskogo St., 38

\section{Doi:10.5901/mjss.2015.v6n3s3p193}

\section{Abstract}

The paper is concerned with issues of methodological support of selection of preferred option of production strategy. Russian oil production enterprises are the study object. The paper provides characteristics of current business environment, main features of running oil and gas organizations are stated, the need for timely flexible strategic decision making in the area of production management given the specific features of industry companies is proved. Moreover, the problem of the lack of available theoretical and methodological instruments of management decision making, the need for their adaptation to operational environment of stated business entities is revealed. It's stated that complex changing conditions predetermine special requirements for these instruments. Particularly, methodological approaches are needed that allow making decisions according to various criteria. Given this, criteria may confront each other. The technology of multiobjective optimization is chosen as a basis for further modification. The paper attempts to integrate strategic and production management, and also management decision making theory by means of considering local (partial) performance indicators of production organization target strategic parameters of production strategy. Subsequently suggested indicators will be used as measuring means when choosing the preferred variant of decision based on multiobjective optimization methods. Recommendations concerning objective function generation, analysis and adjustment of partial criteria for adding into estimation model. It's proved that target and secondary business processes should be considered interrelated and interdependent for the purpose of production strategy elaboration due to specific nature of oil producing companies' core operations organization. Therefore, estimation models are developed correspondingly. In conclusion author's research guidelines are stated.

Keywords: multiobjective optimization, production strategy, production organization and management, oil production enterprises, methodological approaches.

\section{Introduction}

Under current conditions of widening changes in the area of companies and organizations operation the issue of the search for valid methodological instruments that allow making relevant strategic decisions providing company's survival and success both in the short and long terms becomes pressing. For example, some foreign companies, which recently have successfully developed shale production projects, have found it difficult and have to suspend execution of these projects due to evolving situation on the world market of raw hydrocarbons. For this reason many oil and gas companies of various countries have to revise their business strategy. Interestingly, it is referred to sufficiently large companies of multilevel structure, internal construction complexity, specific nature of operation. For these companies instruments of strategic decision making should meet the following requirements:

- $\quad$ to consider specific external and internal features of operation of the subject of research;

- $\quad$ to provide possibility of multivariate decisions generation;

- $\quad$ to allow making decisions with regard to various criteria and factors, examining assumed consequences from decision implementation for the organization comprehensively and in an integrated manner;

- $\quad$ to take into account time limits for decision-making, since time in these cases is strategic resource.

The analysis of numerous literary sources on the issue of management decision-making shows that the technology of multiobjective optimization is one of the most reasonable instruments for specified problem solution. 
It is worthy of note that in the modern theory of management much attention is given to strategic decisions making at the level of parent companies. Main problems arise when it is necessary to decompose company-wide strategic decisions to functional level, and when elaborating and making decisions by functional areas of activity. The paper examines the methods of multiobjective optimization potentials adaptation to production (organizational technological) strategy of the oil and gas company. The choice of this functional strategy is caused by the high importance of production unit for these branch business entities.

We emphasize that in the modern period of Russian oil producing enterprises development efficiency of production strategy development is complicated by weak information database on production processes history and corresponding criteria. In most cases oil producing organizations carry out incomplete analysis of economic activity, wherein estimation of production organization is reflected poorly. As a rule, actual values of technical-economic indicators of operation are analyzed against their conformity to target values (Yakunina O.G., 2014). It doesn't provide the broad and accurate picture of production state in general and production organization in particular, that, in its turn, prevents revealing its defects and offering efficient measures within updating program.

In regard to abovementioned circumstances it turns necessary and possible to systematize and specify indicators, which can be used in the process of analysis of existing organization state and production management at oil production enterprises. Organizational level diagnostics is focused on the problem areas detection and grounding reorganizational measures intended to improve production organization and management effectiveness in the area of oil production. Moreover, formed complex of indicators can be useful for reasoning choice of the most preferred option of business development in accordance with set goals.

\section{Literature Review}

Currently the theory of management has gained considerable experience in the area of strategic managements issues. The issues of strategic decisions development are revealed in many research papers of such well-known foreign scientists as Albert M., Ackoff R., Ansoff I., Doyle P., Drucker P., Cahall I., Lambin J.-J., Laft J.K., Mescon M., Mintzberg H., Oldcorn R., Payton R., Porter M., Strickland A.J., Thompson A.A., Trayson D., Waterman R.H., Phillips J.R., Khedouri F., Chandler A., Andrews K. and others (Albert K., 1983; Ansoff I., 1979; Ackoff R., 1981; Doyle P., 1994; Drucker P., 1974; Lambin J.-J., 1993; Mescon M., 1988; Mintzberg H., 1996; Porter M., 1987; Thompson A., 1957)

Among Russian authors the role and contribution of strategic management in companies' operation are demonstrated in the works of Azoev G.L., Vihansky O.S., Gradov A.P., Efremov V.S., Knysh M.I., Kruglov M.I., Lyukshinov A.N., Naumov A.I., Petrov A.N., Rumyantseva Z.P., Salomatin N.A., Sterlin A.R., Tulin I.V., Utkin E.A., Fathutdinov R.A. and other scientists (Vihansky O.S., 1998; Efremov V.S., 1998; Kruglova N.Ya., Kruglov M.I., 2003; Lyukshinov A.N., 2000; Petrov A.N., 2005; Fathutdinov R.A., 2005).

The model of production strategy was developed by the researches of Harvard business school William Abernathy and Kim Clark and others based on the earlier studies of Wickham Skinner at the end of the 70s and at the beginning of the $80 \mathrm{~s}$ of the $20^{\text {th }}$ century. Further conceptual framework of production strategy development was reflected in the works of Chase R.B, William J., Makarenko, M.V., Makhalina O.M., Minaev E.S., Ageeva N.G., Goldstein G.Ya. and others (Chase R.B, Equiline N.J, Yacobe R.F, 2004; Makarenko, M.V., Makhalina O.M., 1998; Minaev E.S., Ageeva N.G., Abbate D.A., 2000; Goldstein, G.Ya., 2004).

The analysis of literary sources shows that both national and foreign scientists agree that production strategy is closely connected with general (corporate) strategy focused on enterprise's production operation, and in most cases its components are production organization and management, production staff and product quality control.

There are various approaches to the definition of decision optimality, such as ordinalistic and cardinalistic approaches, which are examined in detail in the works of Berezovsky B.A., Baryshnikov Yu.M., Borzenko V.I., Kepner L.M., Podinovsky V.V., Nogin V.D., Bezruk V.M. et al. (Berezovsky B.A., Baryshnikov Yu.M., Borzenko V.I. et al., 1986; Nogin V.D., 2004; Bezruk V.M., Bukhanko A.N., 2012).

For the first time classification of multiobjective problems based on solution method was made by Hwang and Yoon and is partially represented in the Zak's work (Zak Yu.A., 2014). The works of Steuer R., Keeney R.L., Raiffa H., Lotov A.V., Pospelova I.I., Zinovyeva, E.G., Dubovskoy K.I., etc. are concerned with various aspects of multi-objective problems solution.

Issues relating to estimation technique of organizational level of production are always been represented in the works of national and foreign scientists. The analysis of organizational level provides means for identifying improvement opportunities for production organization and make better decisions focused on optimization of production systems operation. 
To date Russian practice has sufficiently large amount of methodological developments concerned with estimation of the level of production organization, management, and labour. Methodological approach is the most popular in the works of Russian scientists including Andreev A.F., Brents A.D., Tishhenko V.E., Malyshev Yu.I., where an emphasis is put on the need for accounting basic principles of rational organization of production, such as proportion, rhythmicity, continuity (Andreev A.F., 1995; Brents A.D., Tishhenko V.E., Malyshev Yu.I., 1986). It's suggested to quantitatively interpret these parameters based on coefficient approach, wherein indicators' values vary from 0 to 1 . In such a case, each author individually forms content and number of partial indicators.

Nonetheless, against the background of common moments typical for different methods, there are fundamental differences. For example, a number of authors recommend to estimate levels of organization, management, and labor separately, and then to calculate the resulting indicator of organization level on the basis of indicators characterizing that levels. According to other methods this indicator is directly defined based on the aggregate of partial indicators that reflect both production organization and labour organization (Stepanov I.G., 2003).

It should be pointed out that formation of methodological approaches to organizational level estimation has been carried out in interrelation with dynamically changing economic conditions of Russian enterprises' development. For this reason key points of research studies have began to shift towards evaluation of technologic component of production system as a result of rapid implementation of new technologies and switch to innovation-based development of the Russian economy. Thus, estimation technique includes the term of "organizational and technical" level of production (Fathutdinov R.A., 1997).

Foreign practice exercises somewhat different approach to production organization and management level estimation. Production system and its components are considered in terms of operations management. Richard Chase, Nicholas Equiline, Robert Yacobe define operations management as operations related to development, use and enhancement of production systems based on which the company's main product or services are produced (Chase R.B., Equiline N.J., Yacobe R.F, 2004). Therefore, production system management is a base of operations management.

The structure of production system includes operating resources, so-called 5Ps of operations management: people, plants, parts, processes, planning and management systems. If we enlarge these components and represent them in a somewhat different way, it will be the following: production organization and management, production staff, and product quality control. These components combined present the matter of evaluation for the purpose of production and management effectiveness estimation in the framework of operational strategy.

\section{Materials and Methods}

\subsection{System of evaluation indicators}

The task of assessment of alternative decision making often arise in actual management practice, especially when making strategic decisions in the field of production by several criteria (Osinovskaya I.V., Lenkova O.V., 2015). This problem is studied using decision and decision-making theory based on multi-objective problem solution (Plenkina V.V., Andronova I.V., Osinovskaya I.V, 2009). However, the use of multiobjective approach is impossible unless a system of evaluation indicators is developed that is scarcely a simple task. This task should be solved for each case independently. In this paper the multiobjective technology will be transformed for the purpose of production strategy alternative selection in terms of the search for preferred alternatives of specified strategy.

On the assumption that strategy is a means for achievement of company's objectives, we try to interlink the procedure of strategic alternatives selection with the process of objectives setting. Then according to the author's logic, production strategy is focused on achievement of objectives in the area of production, which, as previously mentioned, can deal with production organization and management, production staff and product quality control. In view of its complexity and significance, each of enumerated components can be a subject matter. Within the framework of this paper only production organization and management are considered.

Production organization is traditionally understood as rational combination of facilities, subjects of labour with organization of technologic and natural production processes in space and time. The lack of single performance criteria of production organization and management should be emphasized. There is no universal system of evaluation criteria for organization level analysis of main and auxiliary production. It is assumed that every production system is unique and system of evaluation indicators is formed based on the characteristics of system operation, objectives and tasks to be solved.

In this regard if we state the need for improvement of production organization effectiveness as main functional objective in the area of production, then objective need for complex indicator of this effectiveness evaluation appears. It's 
practical to derive this indicator by aggregation or convolution of partial indicators of efficiency. Selection, grouping and generalization of indicators are also quite a challenge. In our opinion, its solution should be based on the use of productions, which include study of forms, methods, and principles of production organization; business processes and works' organization quality; production efficiency from a perspective of optimal technical-and-economic indicators achievement (costs, overall production, etc.) in the selection process of organization's current theoretical and methodic aspects. For that matter the authors consider it expedient to develop the system of evaluation indicators within separate units that reflect abovementioned trends and include a number of partial subcriteria. Subsequently, using subcriteria production system operation in general and also its sybsystem - main and auxiliary (maintenance, transport, power supply) productions, logistical support sybsystems (or production logistics) can be evaluated.

Eventually the process of objectives setting and breakdown of the general production objective into subobjectives (objectives tree construction) can be carried out based on the results of evaluation on the principle of "strategic gaps" detection. In other words, in this case objective of production organization effectiveness improvement can be easily decomposed by units and subobjectives. Given this, each subcriterion with detected "strategic gaps" will have corresponding subobjective. It's important that this technique largely allows shifting from qualitative objectives setting to quantitative ones. It is recognized that the main disadvantage of qualitative objectives is complicacy of their measurability and/or formalizability (nonconformance to SMART principles) that in particular cases makes them unfit for the purposes of monitoring objectives achievement.

Regarding strategic decisions formation it's also important to mention importance of strategic analysis by research object's areas of business. As a rule, results of the analysis form the basis for "strategic gaps" detection and ground for objective setting.

Depending on the number of subcriteria entering each evaluation unit one may consider express-estimating (for example, by 2 criteria in each unit) or carrying out detailed comprehensive analysis of production system operation. Obviously, it will condition the number of levels in objectives tree, their range and also the range of possible strategic alternatives focused on detected problems solving and set objectives achievement correspondingly.

Taking into account specific nature of objective business processes in oil production expressed in strong interrelation and interdependence on auxiliary operations quality, classification of indicators for organizational level diagnostics is carried out by the example of auxiliary production. The authors suggest classifying and grouping indicators depending on criterion direction and set tasks for the purposes of strategic analysis of production unit of oil-production enterprise's internal environment with regard to organizational level of auxiliary production by its types (Fig. 1).

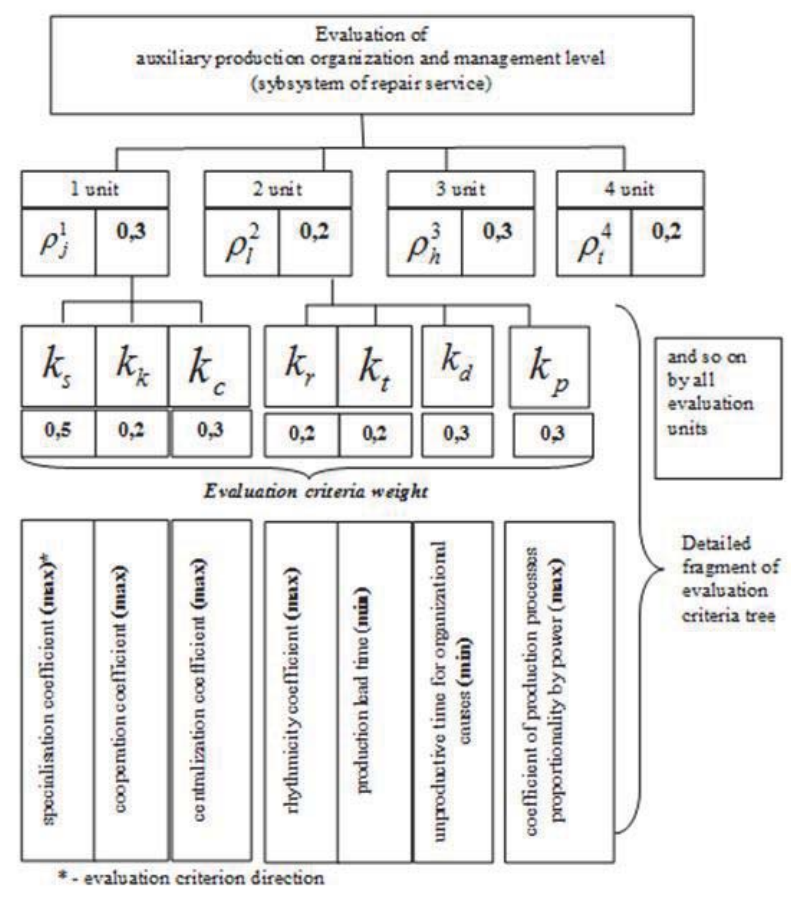

Fig. 1. Tree-like system of evaluation indicators (subcriteria) 
On the one hand, the suggested set of indicators includes most unified characteristics of the object, and on the other hand individual indicators typical for specific types of services. Thus, the evaluation system includes 4 units that characterize

- the use of forms of production organization and management, $Y_{1}^{F}$ (1 unit);

- the use of rational production organization principles, $Y_{2}^{P}$ (2 unit);

- $\quad$ timing and quality of execution of works, $Y_{3}^{Q}$ (3 unit);

- $\quad$ effectiveness (efficiency) of production and management, $Y_{4}^{E}$ (4 unit).

As mentioned above, this system of evaluation criteria, largely used for organizational diagnostics, can be transformed in "objectives tree", and appearance of weight coefficients in this case is for a reason. By establishing weight coefficients it's possible to consider specific nature of the studied type of activity, conditions (including external ones) of strategic decisions selection, significance (priority, weight) of each parameter under the general objective, etc. As a rule, weight coefficients are established by expertise. We see it fit to support expert evaluation with such techniques as, for example, pair-wise comparison, etc.

It also makes sense to use given set of evaluation criteria for selection of the most preferred variant of production strategy implementation.

\subsection{Multiobjective model of evaluation of repair service organizational level}

As it's clear from given above system of evaluation indicators, selection of strategic decisions often involves the complicate search for optimal decision since within this decision the coordination of many criteria (objective parameters) is necessary, some of these criteria can be opposite to each other. In this regard possibility of optimal management tasks solution by several objective criteria becomes actual (Lyaskovsky A.V., 2007). In this case optimization is considered selection of the best option from the variety of possible alternatives in the course of bringing the production system to best (desired) condition.

The main challenge that arises when solving the set task is derivation of mathematical formulation of utility function (Steuer R., 1992). According to utility theory this function is calculated as a stochastic quantity, herewith, this approach is extremely difficult to implement in practice for troublesome production and management tasks solution. That's why utility function can be considered not stochastic, but standardized quantity, wherein membership function is considered to be subjective estimation of a decision maker (DM) (Kuzin B.I.., Yuyev V.N., Shakhdinarov G.M., 2001). For this purpose the system of evaluation criteria and subcriteria should be brought to dimensionless form using the following formula:

$$
k_{i}=\frac{k_{i}-k_{i}^{\min }}{k_{i}^{\max }-k_{i}^{\min }},
$$

Where $k_{i}^{\text {max }}, k_{i}^{\text {min }}$ - maximum and minimum values of the $i^{\text {th }}$ criteria correspondingly.

Multi-objective problem appears because of impossibility to define upper or lower limit at the stage of task setting. In this case the indicator loses its constraining condition and takes the role of additional criterion, which should be minimized or maximized. Such tasks are solved by its bringing to one-objective state using one of the following methods (Reznichenko S.S., Podolsky M.P., Ashihmin A.A., 1991):

- introducing a complex criteria that unites all performance indicators into one function;

- successive solutions of the problem one-by-one with different criteria and search for some compromise between results.

The key feature of multi-objective problems is uncertainty relating to the need of comparison by several criteria (Plenkina V.V., Andronova I.V., Osinovskaya I.V., 2009). Solution of multi-objective problems usually involves the search of compromise decision. Regarding compromise decisions it's impossible to achieve simultaneous improvement of the decision by all parameters. Pareto approach to optimal decisions can be interesting to define the area of compromise decisions. It suggests that optimal decisions are decisions that have not worst values by all criteria, but the best value by one than other alternatives. Detection of Pareto optimal decisions usually allows reducing the number of considered alternatives.

Quantitative methods of multi-objective problems solution are based on the introduction of single complex optimality criterion (value function) that allows evaluating compared variants unambiguously. Therefore, the problem of multiobjective optimization is reduced to one-objective one. Linear value function is widespread (additive criterion), which is derived in a following way (Plenkina V.V., Andronova I.V., Osinovskaya I.V., 2009): 


$$
V=\sum_{i=1}^{N} w_{i} k_{i}=w_{1} k_{1}+\ldots w_{i} k_{i}+\ldots w_{n} k_{n},
$$

where $i$-optimality criterion index,

$W_{i}$ - weight (importance) of the $i^{\text {th }}$ subcriterion. Relative weights are usually used, i.e. $\sum_{i=1}^{N} w_{i}=1$.

$k_{i}-$ value of the $i^{\text {th }}$ subcriterion, if $k_{i}$ - whole numbers, the method will be score one.

For the purpose of the stated problem solution based on the use of the set of subcriteria by each evaluative unit for repair service subsystem shown in Fig. 1, it was suggested to carry out additive convolution of partial indicators. Based on this convolution we managed to derive integral criterion by each evaluative unit, as well as complex criterion in general by production system under study (3-7):

unit 1: $Y_{1}^{F}=\sum_{j=1}^{m} \rho_{j}^{1} * k_{j}=\rho_{1}^{1} * k_{s}+\rho_{2}^{1} * k_{k}+\rho_{3}^{1} * k_{c} \longrightarrow \max$

unit 2: $Y_{2}^{P}=\sum_{l=1}^{k} \rho_{l}^{2} * k_{l}=\rho_{1}^{2} * k_{r}+\rho_{2}^{2} * k_{t}+\rho_{3}^{2} * k_{d}+\rho_{4}^{2} * k_{p} \longrightarrow \max$

unit 3: $Y_{4}^{E}=\sum_{t=1}^{g} \rho_{t}^{3} * k_{t}=\rho_{1}^{3} * k_{k r}+\rho_{2}^{3} * k_{a}+\rho_{3}^{3} * k_{p c}+\rho_{4}^{3} * k_{p k}+\rho_{5}^{3} * k_{t r} \longrightarrow \max$

unit 4: $Y_{3}^{Q}=\sum_{h=1}^{r} \rho_{h}^{4} * k_{h}=\rho_{1}^{4 *} k_{\text {iot }}+\rho_{2}^{4} * k_{a r}+\rho_{3}^{4} * k_{s c}+\rho_{4}^{4} * k_{m c} \longrightarrow \max$

$K_{\text {op }}=\sum \alpha_{i} * Y_{i}=\alpha_{1} * Y_{1}^{F}+\alpha_{2} * Y_{2}^{P}+\alpha_{3} * Y_{3}^{Q}+\alpha_{4} * Y_{4}^{E} \longrightarrow \max$

where $\rho_{j}^{1}, \rho_{l}^{2}, \rho_{h}^{3}, \rho_{t}^{4}$ - weight of evaluation subcriteria, entering units No.1, 2, 3 and 4 correspondingly;

$k_{j}, k_{l}, k_{h}, k_{t}$ - evaluation subcriteria entering units No. 1, 2, 3 and 4 correspondingly;

$m, k, r, g$ - the number of evaluation subcriteria comprising unit No. 1, 2, 3, 4 correspondingly;

$j=1,2 \ldots m ; l=1,2 \ldots k ; h=1,2 \ldots r ; t=1,2 \ldots g$;

$k_{s}$ - specialization coefficient (max). Hereinafter criterion direction is indicated within brackets, i.e. what result is considered the best by operations managers by analyzed subcriterion;

$k_{k}$ - cooperation coefficient (max);

$k_{c}$ - coefficient of functions centralization by type of service (max);

$k_{r}$ - service rhythmicity coefficient (max);

$k_{t}$ - production lead time (min);

$k_{d}$ - unproductive time for organizational causes (min);

$k_{p}$ - coefficient of production processes proportionality by power (max);

$k_{k r}$ - repeated repairs coefficient ( $\left.\mathrm{min}\right)$;

$k_{a}$ - accident coefficient (min);

$k_{p c}$ - coefficient of meeting the functional subdivisions scope need with established production capacities (max);

$k_{p \kappa}$ - work progress coefficient (max);

$k_{t r}$ - mechanical availability coefficient (max);

$k_{\text {iot }}$ - extraction volume gain due to repairs time reduction (max);

$k_{a r}$ - incremental and reconditioned oil production after well servicing (max);

$k_{s c}$ - share of service expenses in oil net cost (min);

$k_{m c}$ - administrative unit costs (min).

It is necessary to point out that quality indicators, which can be included in the $3^{\text {rd }}$ evaluative unit, are dependent against each other and conflicting (Bezruk V.M., Bukhanko A.N., 2012). 
Weight coefficients of each subcriterion in the model are defined in the same manner as weight coefficients of subobjectives with regard to each subcriterion, enterprise's particular characteristics and other factors. Given this, cumulative value of all weight coefficients within each unit should be 1 (Marler, Arora, 2004).

Moreover, in this case value function is constructed by additive principle, although the use of multiplicative approach to its construction is possible. Subcriterion sign should be considered in both models of value functions. For example, if subcriterion records negative factors (qualities), it should be included in additive criterion with minus sign or considered in denominator when using multiplicative model.

It should be noted that the use of multiobjective optimization methodology makes it possible to get values of partial and complex criteria by each level in general and by subsystem under study in particular. This suggests possible increase in management decision making efficiency in the area of production management, estimation of objective achievement by each subsystem, more rational allocation of limited resources in implementing strategy.

The approach suggested by the authors is sufficiently universal and can be applied to estimate level of organization of both main and auxiliary production. In spite of the fact that testing of approach under discussion was carried out by the example of oil producing enterprise, it can be used at enterprises of various fields. Given the specific features of their operational systems managers can introduce corresponding adjustments to the set of indicators that form evaluation system by distinguished evaluation units and attach corresponding significance to them depending on issues to solve or objectives to achieve.

\section{Results}

In the course of the study the authors developed a complex of criteria for evaluation of oil production enterprise's organization level. It was recommended to use this set of indicators to define objectives and create the objectives tree, to carry out strategic analysis of oil company's internal environment, particularly, production unit, and also for the purpose of evaluation and multiobjective selection of preferred option from possible strategic decisions. Value function for construction of complex criterion of production organization performance (level) is proposed. Recommendations for its application are given.

The described and considered authors' approach to organization level evaluation can help executives of different managerial levels, economists, functional managers to accept timely, well-founded, balanced decisions in the area of production strategy formation.

\section{Discussion}

The problem of multiobjective evaluation of enterprises' different subsystems operating efficiency have been discussed by national (Nogin V.D., 2004, Biryukov A.N., 2010 et al.) and foreign authors (Steuer R., 1992, Marler, R.T., Arora, J.S., 2004 et al.) for more than one decade. Application aspects of theoretical and methodic foundations of multiobjective optimization are sphere of various scientists' interest. The use of this approach in production system evaluation is quite a challenge since operation of this system should be evaluated regarding various aspects: technological, economical, social, personnel, strategic, innovative etc. Besides, evaluation involves the use of a set of differently directed subcriteria (Biryukov A.N., 2010) that may exceed several dozens. Within multiobjective optimization a case when optimal decision is reached by all subcriteria is unlikely. For such problems it's typical that alternatives or possible decisions with best values of one group of subcriteria, as a rule, lead to degradation of subcriteria values of other group (Zak, Yu.A., 2014).

Ambiguous attitude to multiobjective approach use observed regarding linear and functional managers coming from some subjectivity when setting weight coefficients of corresponding subcriteria, and also evaluation indicators system dependence on a decision maker. For this reason we find it possible and expedient afterwards to seek for and adapt corresponding economical-mathematical tools to decrease the degree of subjectivity when making such-like strategic decisions.

Besides, according to our reckoning, the issue of environment status accountability, which is of paramount importance for strategic decisions, remains unrevealed. It can be supposedly amended by linking and changing weight coefficients of evaluation criteria or when performing procedure of criteria normalization for convolution in value function, or introducing additional constraint system.

\section{Conclusion}

In conclusion we'd like to mention that stated objective of the study that involved developing methodic foundations for 
preferred alternative selection in the area of oil enterprises' production strategy is achieved. On the basis of thorough analysis of current approaches in the area of strategic and production management and management decision making theory the choice of multiobjective optimization technology as main methodical instrument with regard to its adaptation to oil producing companies' business environment is proved. Value function and the system of evaluation indicators were suggested for diagnosing current level of production organization, setting corresponding objectives, developing evaluation criteria and selecting preferred variant. Recommendations for author's methods application and its further development are provided.

In our opinion, one of disadvantages of the authors' proposals is high labour intensity of calculation and analytical procedures, which can be reduced by partial or full automation. We disregard model simplification by decreasing the number of estimated parameters as a method of stated drawback leveling as it can lead to increase in subjectivity and decrease in practical value of results obtained when using this model. At the same time the model has significant advantage - flexibility, universality, possibility of its adjustment to specific features and requirements of various business entities.

This model got partial approval in one of subdivisions of oil producing company's auxiliary production. Diagnostics of existing state of organizational level made it possible to outline strategic alternatives when developing production strategy, namely, to give reasons for selection of preferred variant of both external and internal reorganization, providing the balance of company's main and auxiliary departments' interests. Particularly, antipodal variants relating to spin-off of non-core subdivisions from parent company (external reorganization) on the one side, and realization of inner transformations within the company on the other side were in the purview. For example, regarding the latter, there's concentration of service production by creating administrations by type of activities within the oil producing company (internal reorganization).

Based on the use of methodic approach proposed by the authors we managed to develop combined production strategy, which maximally corresponded to the company's strategic objectives at the definite stage of its development.

\section{References}

Ackoff, R.L. (1981). Creating the Corporate Future: Plan or Be Planned for. New York: John Wiley \& Sons, 279 p.

Albert, K.K. (1983). The Strategic Management Handbook. New York: McGraw-Hill.

Andreev, A.F. (1995). Organization and Planning of enterprise operation under market conditions. Moscow: information advertising center Gazprom.

Ansoff, I.H. (1979). Strategic Management. New York: Wiley.

Berezovsky, B.A., Baryshnikov, Yu.M., Borzenko, V.I., Kepner L.M. (1986). Multicriteria optimization. Mathematical aspects. Moscow: Nauka, $128 \mathrm{p}$.

Bezruk, V.M., Bukhanko, A.N. (2012). Taking optimal decisions in telecommunications networks with due account for a complex of qualitative indicators // Electronic academic specialized publication. - Problemy telekommunikatsy, No.(6), URL: http://scipeople.ru/publication/108708/ (access date 09.01.15)

Biryukov, A.N. (2010). Multiplicatively additive convolution of partial criteria-aggregates for health care facilities operation evaluation // Upravlenie ekonomicheskimi sistemami, No.4, URL: http://www.uecs.ru/logistika/item/275-2011-03-25-06-56-54 (access date 11.12.14)

Brents, A.D., Tishhenko, V.E., Malyshev, Yu.I. et al. (1986). Oil and gas industry enterprises organization, planning and management. Moscow: Nedra, $511 \mathrm{p}$.

Chase, R.B., Equiline, N.J., Yacobe, R.F. (2004). Production and operational management, $8^{\text {th }}$ issue. Translated from English: Moscow: "Williame" publishing house, $704 \mathrm{p}$.

Doyle, P. (1994). Setting Business Objectives and Measuring Performance. // Journal of General Management, 20, No.2, (Winter), pp. 119.

Drucker, P.F. (1974). Management: Tasks, Responsibilities, Practices. New York: Harper \& Row, 839 p.

Efremov, V.S. (1998) Business strategy. Planning conceptions and methods. Moscow: "Finpress", 192p.

Fathutdinov, R.A. (1997). Production management: Textbook for HEI. Moscow: Banki i birzhi, UNITY, 447 p.

Fathutdinov, R.A. (2005). Strategic management. Textbook. $7^{\text {th }}$ edition, revised. Moscow: Delo, 448 p.

Goldstein, G.Ya. (2003). Strategic management: Textbook, $2^{\text {nd }}$ issue, enlarged. Taganrog: Taganrog State Radiotechnical University Press, $94 \mathrm{p}$.

Keeney, R.L., Raiffa, H. (1981). Decision-making with many criteria: preferences and substitutions: translated from English / Ed. by Shakhnov I.F. Moscow: Radio i svyaz.

Kruglova, N.Yu., Kruglov, M.I. (2003). Strategic management. Text book for higher education institutions. Moscow: RDL, 464 p.

Kuzin, B.I., Yuryev, V.N., Shahdinarov, G.M.. (2001). Company management methods and models. St. Petersburg: Piter.

Lambin, J. J. (1993). Strategic marketing. A Euro approach / De Bono E. J. London: McGraw-Hill Book Co., 539.

Lotov, A.V., Pospelova, I.I. (2008). Multi-objective problems of decision-making: textbook. Moscow: MAX Press, 197 p. 
Lyaskovsky, A.V. (2007). Organization marketing activity multiobjective management. [Electronic resource]: Publishing house Education and Science s.r.o. URL: http://www.rusnauka.com/20_PRNiT_2007/Economics/23721.doc.htm (access date 20.12.14)

Lyukshinov, A.N. (2000). Strategic management. Textbook for HEI. Moscow: Unity-Dana, 375 p.

Makarenko, M.V. (1998). Production management: Textbook for HEl / Makarenko M.V, Makhalina 0.M. Moscow: Prior, 384 p.

Marler, R.T., Arora, J.S. (2004). Survey of multi-objective optimization methods for engineering. Structural and Multidisciplinary Optimization 26, pp. 369-395.

Mescon, M. H., Albert, M. H., Khedouri, F. H. (1988). Management. New York: Harper \& Row, 777 p.

Minaev, E.S. et al. (2000). Production and operations management. 17- modules program for managers Organization development management/ Minaev E.S., Ageeva N.G., Abbate Daga A. Moscow: INFRA-M, 256 p.

Mintzberg H., Quinn J. B. (1996). The Strategy Process: Concepts and Contexts. Upper Saddle River, N.J.: Prentice Hall, Co., 990 p.

Mustakerov, I., Borissova, D., Bantutov, E. (2012). Multiple-choice decision making by multicriteria combinatorial optimization // AMO Advanced Modeling and Optimization, Vol. 14, No. 3, pp. 729-737

Nogin, V.D. (2004). Decision-making in multiobjective environment: quantitative approach. $2^{\text {nd }}$ edition, revised. Moscow: FIZMATLIT, $176 \mathrm{p}$.

Osinovskaya, I.V., Lenkova, O.V. (2015). The technological development of managerial decisions on the productive capacity of oil producing industrial building structures// International Business Management, No.9, pp.164-168

Petrov, A.N. (2005). Strategic management. St. Petersburg: Piter, 496 p.

Plenkina, V.V., Andronova, I.V., Osinovskaya, I.V. (2009). Management decisions. Tyumen: Tyumen State Oil and Gas University 160 p.

Porter, M.E. (1987). From Competitive Advantage to Corporate Strategy. // Harvard Business Review, (May-June), pp. 43-59.

Reznichenko, S.S., Podolsky, M.P., Ashihmin, A.A. (1991). Economic and mathematical methods and modelling in mining planning and management: Textbook for HEl. Moscow: Nedra, $429 \mathrm{p}$.

Stepanov, I.G. (2003). Organization of production: Textbook / Kemerovsky State University. Novokuznetsk, 93 p.

Steuer, R. (1992). Multicriteria optimization. Theory, calculation and application. Translated from English: Moscow: Radio i svyaz, 504 p.

Thompson J.D., Bates F.L. (1957). Technology, Organization, and Administration. // Administrative Science Quarterly, No. 2, pp. 235242.

Thompson, A.A., Strickland, A.J. (1998). Strategic management. The art of strategy development and implementation. Moscow: Banki i birzhi, UNITY, $579 \mathrm{p}$.

Vihansky, O.S. (1998). Strategic management. Textbook. $2^{\text {nd }}$ edition., revised and corrected. Moscow: Gardarika, 296 p.

Yakunina, O.G. (2014). Evolution of methodological approaches to estimation of production organization level and management of oil production enterprises // Ekonomika i predprinimatelstvo, No.11-2, pp. 512-516.

Yarygin, A.N., Kolacheva, N.V., Palferova, S.Sh. (2013). The methods of optimal solving economic tasks of multiobjective optimization. URL: http://edu.tltsu.ru/sites/sites_content/site1238/html/media90388/86Yarygin.pdf (access date 15.12.14)

Zak, Yu.A. (2013). Decision-making in the context of imprecise and fuzzy data: Fuzzy-technologies. Moscow: publishing house "LIBROKOM", $352 \mathrm{p}$.

Zak, Yu.A. (2014). Application tasks of multiobjective optimization. Moscow: Ekonomika.

Zinovyeva, E.G., Dubovskoy K.I. (2012). Practical application of mathematical methods for solution scheduling issues in management /I Vektor nauki TGU. Series: Ekonomika i upravlenie, No.4, pp. 65-67. 
ISSN 2039-2117 (online) ISSN 2039-9340 (print)
Mediterranean Journal of Social Sciences MCSER Publishing, Rome-Italy
Vol 6 No $3 \mathrm{~S} 3$ May 2015 